\title{
Seismic Shifts: A Structural Health Monitoring Textile
}

\author{
Kate Cheyne \& Kirsty McDougall
}

Department of Architecture, University of Brighton, Brighton, UK and Textiles

Programme, Royal College of Art, London, UK

This research was supported by University of Brighton, Research Challenges Scheme, awarded to Dr Joan Farrer, Professor Susannah Hagan, Kate Cheyne, \& Kirsty McDougall.

Correspondence concerning this article should be addressed to Kate Cheyne, Department of Architecture, Third Floor, Mithras House, University of Brighton, Lewes Road, Brighton, BN2 4GJ. E-mail: k.cheyne@brighton.ac.uk.

Kate Cheyne is a UK based architect and Deputy Head of School of Architecture and Design at the University of Brighton. Educated at the Bartlett, University College of London, she worked in architectural practices in London, Israel and Sri Lanka, predominantly focussing on healthcare and housing projects, before co-founding and jointly directing the award winning practice - Architects In Residence (A.I.R.) At A.I.R. she set up diverse cross industry teams ranging from ship builders to fashion designers to develop alternative methods of fabrication. In 2007 A.I.R.s prefabricated solid panel timber housing won the Off-site category at the Wood Awards, the first of its kind in the UK. Following the earthquake in Haiti, Kate worked with Development Workshop France, as consultants to Save the Children USA, designing transitional schools that incorporated safer construction methods. In 2010 she moved her practice knowledge into research and education where she is exploring cultural landscapes, rural industries and, through their growth and adaptation, a new rural architectural vernacular.

Kirsty McDougall is Senior Tutor in Woven Textiles at the Royal College of Art. She is the co-founder of menswear textile brand Dashing Tweeds and director of Kirsty McDougall Woven Textile Design. Her work has been exhibited internationally in museums, on catwalks and in many books and publications. Kirsty won a Jerwood Prize in 2010 and Dashing Tweeds won a Scottish Fashion Award for Textiles in 2012.Kirsty has extensive experience in teaching and mentoring at a wide range of institutions. Her research interests include exploring the combinations of heritage and technology in wool-based textiles; new materials and intelligent textile development; sustainability in UK based fashion and textile design and manufacture and developing new modes of working for the textile designer/ manufacturer. 


\section{Abstract}

This paper describes the fabrication of a novel woven textile with a fully integrated strain-sensitive yarn for application to the built environment as a structural health monitoring system to monitor and ascertain structural damage in real time. The paper presents the context of the use of textiles within the construction industry. It also discusses the strength of using designers as lead researchers in applied science projects, in place of engineers and scientists. The sensor, provided by Nanoforce from Queen Mary University of London, consists of thermoplastic polyurethane fibres containing multi-walled carbon nanotubes extruded as a yarn. This was woven into multiple fabric samples using varying weaves and mix of yarns. The samples were tested for their ability to continuously conduct stable data. The most stable samples were rewoven and set within a resin skin to form a composite material that could later be applied to a building structure. In this paper we evaluate our methodology firstly by analysing the data taken from the initial samples to establish stability of the data acquisition and ascertain the best weave pattern and choice of yarns. Secondly by applying the weave to a resin skin to explore a viable composite material that could be applied to a construction joint within the building industry. (211 words)

Keywords: carbon nanotube thread, textile, composite, strain, earthquake, structural health monitoring system

\section{Introduction:}

This paper describes a multi-disciplinary research project set up within the University of Brighton between the architecture and textile department. The project, named Seismic Shifts, supported two primary objectives. (1). To show proof of concept in the development of a novel woven textile with a fully integrated strain-sensitive yarn. (2). To ascertain if this textile could be used within the construction industry for a structural health monitoring system (SHMS).

To develop this new textile, the research has brought together architects, textile designers, nanotechnologists and engineers, to ascertain if a specialist textile can be designed so that it was possible to embed it into a structural system within the construction industry to sense movement and warn of potential structural failure. The wider ambition is that a smart textile could be 
developed into a sophisticated SHMS that can monitor both the entire building whilst indicating the exact locality and extent of any damage via monitoring and analysis of electrical impulses generated by conductive nano fibres in a flexible textile membrane. This would give both a holistic and detailed picture of the structural integrity of any construction in real time, especially needed post disaster to reduce the cost of human life.

The project began with initial research to consider the use of a strain sensitive conductive carbon nanotube polymer as part of a woven textile, whilst retaining the ability to read constant data from the specialist yarn. The yarn, developed by NanoForce, a spin out company from Queen Mary University of London, was familiar to the team because of previous collaborations. It had not yet been developed beyond a yarn, nor any application considered for it. Once we established the possibility of weaving it into a textile, the complexity of weave and mix of yarns were tested to ascertain the most stable and so most suitable textile to form into a composite material that would be appropriate to build into a structural system for the construction industry. The aim was to make a holistic woven fabric which would:

- Use expertise in woven textiles to harness the specific structure of a weave to tailor the textile for its use, manipulating the direction and degree of stretch and flexibility to suit the needs of the application in construction.

- Control the placement of the yarn within the textile as a designed aesthetic as well as a scientific instrument.

- Propose how the textile would be used as an integrated SHMS for the construction industry.

- For the research to retain aesthetics alongside functionality during the development of the SHMS to enhance the usability.

\section{Structural Health Monitoring Systems:}

The concept of a 'structural health monitoring system' constitutes an industry in itself because of the social and economic need to ensure infrastructure and buildings remain safe to use after a disaster. There is a pressing need for SHMS made of materials that can sense if they have been strained to the point of damage, and report that information in real time to a remote monitor before the structure's safety is compromised. This ability to ascertain any potential or actual structural fault in a bridge or a building reduces both human and economic costs.

The Earth's surface is made up of a series of large plates that are constantly in motion, shifting a few centimetres each year. At the edges of these, intense geological activity builds up, causing volcanoes to erupt and earthquakes to occur. By 2030, 3 out of 5 people will be living in cities, where there will be ever greater concentrations of critical infrastructure, human habitation and capital resources, many in areas prone to high risk geological movement. A large earthquake in Beijing, Los Angeles, or Tokyo is a (inter)national human and economic disaster, and the cost of replacing the existing stock of older and historic buildings and structures would be culturally and economically 
prohibitive. In less economically stable countries, even with considerable improvements to building techniques and quality controls, putting in place a financial model to construct all new buildings to be capable of withstanding severe earthquakes without significant damage is economically doubtful, and structural soundness will continue to be difficult to ascertain post-event, requiring detailed (and potentially inconclusive) site inspections.

SHMS exist in construction as all physical structures move to varying degrees. The monitoring of these movements provides data that can analyse the safety of a structure - architecture or civil engineering. Currently the monitoring is made at a localised area of a structure or a macro overview. The design of a monitoring system as a network of sensors distributed throughout a structure offers the potential of assessing possible dangers in the lead up to a calamitous event as well as the ability to detect the extent of any structural damage following a disaster, and diagnose its stability. The early developments in SHMS consisted of cumbersome mechanical devices attached to structures to collect local data at specific joints. The need, however, is for a holistic picture of damage, as well as localised detail. The interest for a textile that has the properties to both detect strain and transmit data, is that it can be embedded into or onto any structural system both as a dense woven 'patch' or as a distributed network of threads so allowing a parametric image of structural change containing data of both localised and global damage to the structure, static and dynamic.

Structural engineers have investigated various options to achieve this, for example fibre optics or piezo sonor sensors (which are more affordably applied across an entire structure). Fibre optics, or intensity sensors, are rugged, but limited by being low in sensitivity relying only on light and generally can only distinguish on/off characteristics. Interferometric sensors have high sensitivity but are difficult to handle. Using sensors in between these two extremes offers a better option for smart structure applications (Leng, Asundi, 2002).

Our research team were given the opportunity to do this using carbon nano-tube strain sensors, an area of research that is now holding traction in other research institutes. For example, the Centre for Composite Materials at the University of Delaware, have commenced an investigation into the integration of carbon nanotube-based sensing technology into a concrete mix. Our unique viewpoint is in integrating it as a full textile to apply within the building fabric much as a traditional membrane.

\section{The Place for Smart Textiles in the Built Environment:}

Textiles in the built environment have always been an important standard component within the build-up of a building element. They have been integrated into roofs, walls and floors as damp-proof membranes, breather papers and binders, their function being to control water and moisture movement and stabilize other materials. More recently textiles are being used in novel ways as rain-cladding and building finishes, for example London Olympic Shooting Venues by MAGMA architecture (http:/detail-online.com/article) developing on tensile structures led by the innovations in the ' 60 s and ' 70 s by Frei Otto, for example the Munich Olympic stadium (Otto, 1974). They are also finding other innovative uses such as for fabric formwork for concrete structures, for example 
C.A.S.T at University of Manitoba (West, 2016) and most recently the development of fibres as being integral to the structure and form of a building, for example Elytra Filament Pavilion at the V\&A

(https://www.vam.ac.uk/articles). Textile innovation can be seen to be starting to influence architectural design through research in medical textiles (wound care and implantable materials)(Pailes-Friedman, 2016: 107), military textiles (camouflage, protective clothing, defense systems), (Adanur, Tewari, 1997: 348352) fashion wearables by designers such as Helen Storey,(Pailes-Friedman, 2016: 22), Iris Van Herpen and Noa Raviv, (http://journal.fashionspyder.com/the-3d-print-boom-in-fashion-design) fashion textiles and tailoring by designers such as QMilch, AirDye, Vius, Susanne Lee, Upadhyaya, (http://www.treehugger.com/sustainable-fashion) and fine art woven \& crotchet textiles for example the work of Machiko Agano, Toshiko Horiuchi MacAdam, Ernesto Neto (http://scoop.it/t/art-installations). But, despite the growth of research into understanding the effect of human occupation on the environmental performance of a building, the construction industry is slow to expand on the growing knowledge within the wearable textile industry for body monitoring and develop a textile with integrated technology as an intelligent surface to collect real time data. Van Langenhove, Hertleer and Schwarz (2011) noted,

Textiles are extremely versatile in terms of products as well as processes. The building blocks of textile materials (fibres and filaments) are made from a broad range of materials, pure or in combination. Smart configurations and combinations of materials, advanced treatments and technologies lead to specialist properties such as hydrophilic/ hydrophobic nature, antimicrobial and selective permeability. Textile materials are able to combine advanced multi-functionality with traditional textile properties. The objective of smart textile is to absorb a series of active components, essentially without changing its characteristics of flexibility and comfort. Sensors, devices and wires should disappear into the textile......ultimately the fibres and textile structures themselves will become the active elements.

Within the clothing and textile industry, both actively intelligent and passively smart textiles are being produced that adapt to us - our emotions, our smells, our temperature, and our movements. In particular, extensive work has been undertaken with regards to the integration of nano materials to a range of textile outcomes in recent years, as detailed by Sawhany, Condon, Singh, Pang, Li and Hui (2008) who believe that 'Because of its limitless potential in consumer orientated applications, the textile industry is one of the premier beneficiaries of advances in NT (nanotechnology)'.

The application of these advances in intelligent textile development have been most commonly applied to the apparel and medical sectors and concentrate on treatments and finishes and less on construction methods and their effect on the functionality of the textile. Existing work where conductive fibres are incorporated into textiles on a smaller scale and used to monitor the body's vital signs, focuses on the embroidery of the intelligent thread onto the surface of a material (Trindade, Spranger, Martins, Miguel and Santos Silva, 2014). 
But there are industries outside the clothing industry, that are seeing the opportunities in applying these textile innovations. The yachting world has translated the control over the structure of a woven textile into carbon fibre wingsails where the weave is tailored to specific stresses that will be applied to the sails (http://scientificamerican.com). Whilst Formula 1, bike, kayak and boat designers use carbon fibre as a lightweight, but robust, high performance material (http://mclaren.com, http://reillycycleworks.com) At the most advanced end of textile applications, the aeronautical industry is using them as a more integrated and holistic approach to data collection, in the advancement of composite materials that read and respond to the immense physical constraints placed on an airplane or spacecraft, collecting real time data on the stresses and strains placed on the construction (Hehr, Song, Suberu, Schulz, 2014) . Within these industries many new sensors are being developed as distributed sensor networks, including sonar and fibre optics, with the data taken off-site, to give a complete structural picture of any element (Leng, Assundi, 2002)

The development of intelligent composites in other industries indicated that there was the possibility of successfully and safely embedding textiles into the, often crude construction process of architecture. Within construction, the potential use of textiles for the built environment is not only as a scaffold to transport data but also in holding multiple functions within its integration within a building skin build-up, such as use as structural reinforcement or as a damp proof membrane. This would help in reducing material waste, construction time and costs. Drawing on the 'smartness' of traditional textiles alongside the 'intelligence' of future yarns the consideration in the choice of weaves and threads offers this opportunity of the textile being part of an integrated structural or environmental building performance.

To develop a textile based SHMS, our research team were interested in experimenting with fully weaving the strain sensitive yarn into the textile, to maximize the structural properties of a woven material, and avoid a separation between weave and sensor that comes from embroidering the sensor onto the surface of the textile, as seen in previous research groups work such as Mattman, Clemens and Troster (2008). Integrating the sensor fully into a weave, allows it to be applied to the entire building, similar to a membrane, drawing on the analogy of clothing the building, where the textile holds the possibility of not only being an instrument, but as a sophisticated external skin in the evolution of a new architectural language of soft skins and three-dimensional forms. (Ramsgaard Thomsen, 2015)

\section{Integrating a textile into a building:}

When considering the textile as a SHMS the question was how to best apply the textile within a construction process. A full 'wrap' of the structure could allow for collection of data across the construction and give a total data picture of its structural movements. The conception of a complete building system would follow existing building techniques that integrate fabric and paper membranes into the construction build (Fig. 1). The alternative would be whether it should be applied in specific locations designing sequences of textile 'patches', tailored for each structural situation (Fig 2a, 2b). Both alternatives could either be mechanically fixed to the surface of a building structure, or laid onto or into a 
structure by either embedding within plaster or concrete (textile reinforced concrete), or laid into brick joints (brick reinforcement) or laminated on the surface of beams or columns (carbon fibre structural strengthening). The strain sensitive thread would require a protective coating and using the textile with a resin or silicone coating to form a composite material, offers the possibility of the textile to be bonded to a structure whilst protecting the SHMS (Fig. 3).

One line of experimentation was for a textile to be tested as a composite material to ascertain if it could be laid within a protective coating whilst still collecting stable data from the composite. The skin needed to be durable enough to protect the specialist yarn during construction, but flexible enough to sense movement. A requirement of the design of the composite would be to offer a means of attaching the textile to the building structure so that it was fully integrated with it to gain accurate data. Silicone rubber, epoxy resin and latex were all tested as choices to protect the intelligent yarn whilst retaining flexibility and be able to be laminated onto beams and columns (Fig. 4a, 4b).

When selecting a suitable textile within a composite material, it is primarily the loadbearing behaviour that is essential. The loadbearing behaviour is determined by the orientation of the fibres and their waviness (undulations and the weight per unit area $(\mathrm{g} / \mathrm{m} 2)$. Under load, the warp and the weft experience different strains in different directions depending on the type of weave. The placement of warp through the weft greatly affect the mechanical properties of the cloth (Knippers, Cremers and Gabler 2011). In the development of any future composite the consideration of how the structure of a woven textile could be designed to work with, rather than against the structural performance of a building is paramount. If the woven fibres are aligned in the load direction, the textile could be better integrated with the construction detail and so represent more accurately the stresses being applied to the building. The fibre orientation would need to be tailored to the structural requirements at individual joints. A further extrapolation of the results would be to consider if a custom textile construction could be fabricated to achieve maximum functionality of the polymer and tailored to suit the nature of a particular building structure or joint? This thinking offers the possibility that the textile, if fully laminated onto or laid into a building material, could offer a secondary function by offering structural reinforcement by increasing load-bearing capacity as well as monitoring it.

The Seismic Shifts composite was considered as an individual 'glove' (Fig. $5 \mathrm{a}, 5 \mathrm{~b}$ ) for specific joints rather than a complete building surface and further development of the composite will align more with the fibre-reinforced concrete industry and carbon fibre industry than a tensile membrane. Future development will centre around whether the weave can be better tailored, not only in structure, but also in body-fit to fabricate the textile to an exact shape required for specific joints and fixings by using advanced pattern cutting techniques (Fig. 6a, 6b) and 3Dimensional weave, (Fig. 7). Further developments will be in the design of a woven textile pattern that suits a specific structural connection to then be laid into resin and applied to a standard column-to-beam connection. This would then be tested to ascertain the stability of the data transmission through the strain sensitive thread, both when static and dynamic. 


\section{Placing the Strain Sensitive Thread in a Woven Textile:}

The design questions in developing the textile were to make a woven fabric that fully integrated the specialized yarn within the weave. It would use expertise in woven textiles to harness the specific structure of a weave to tailor the textile for its use, manipulating the direction and degree of stretch and flexibility to suit the needs of the application in construction. The research team would also control the placement of the yarn within the textile as a designed aesthetic as well as a scientific instrument.

\section{Design Centric Research:}

For a project that touched on humanities, science and design disciplines, the group needed to bring together a collaborative team made up of designers, engineers and scientists. Research into human-centric design (Norman 2007) and the importance of aesthetics to usability (Norman 2002), underpins the ethos of this project where designers would lead on applying the science of the strain sensitive yarn. Designerly thinking was considered best placed to lead on human-centric design through 'incremental innovation' to bring about 'meaningdriven innovation' (Norman and Verganti, 2012: 2). Seismic Shifts, as a group, was intentionally set up to be led by designers (architects and textile designers) to harness the design methodology of tacit learning through repetition and observation allowing incremental learning. The project merged the conceptual and theoretical idea embedded in Cheyne's previous architectural design work that posited a textile could be an embedded SHMS to self-monitor and self-heal building structures (Cheyne, 1995) with the practice based design knowledge of McDougall's weaves that mix technical and traditional yarns (McDougall, 2011). Structural engineers and material scientists were brought in as consultants during the development of the textile.

The project avoids the textile being developed purely as a functional instrument and considers the aesthetic qualities of the textile throughout its development, to ensure the experience of it is central to the usability for a nonexpert. The research team acknowledges that aesthetics effect how humans react to an object and how they influence the users' understanding and emotions (Norman, 2002). As the need for a SHMS was essentially human - to allow people to know if a structure was safe and so save lives, it was felt that the understanding of the textile should be made immediately accessible to everyone through an application of the textile that would have visual clarity, both physical and digital, and that aesthetics needed to be considered alongside functionality.

\section{Understanding the Strain Sensitive Yarn:}

The initial development of a new intelligent textile for a SHMS required clear understanding of the strain sensitive yarn that was to be integrated. The aim was to ensure that appropriate weaves and yarns were used within the final textile to guarantee the ability to retain the readability of stable and constant data from the base yarn. 
This yarn, conceived, developed and fabricated at Nanoforce, Queen Mary University of London is a conductive carbon nanotube polymer composite (Zhang, Bilotti, Deng, Baxendale, Peijs 2009). It acts as a sensor formed as a group of extruded fibres held within a nano carbon tube that has the ability to sense strain and conduct the data back to a computer for analysis. It had not yet been integrated into a textile structure, and no applications had been developed for its use.

Nanoforce had previously proven that this yarn can predict the conductivity of the nanocomposite fibres and has a 'tune-able' level of electrical conductivity. The same TPU/CNT fibres also demonstrate good transmitting capabilities in strain-sensing. It is this ability to sense strain that has driven the research into the possibility of it being applied as an intelligent sensing web or textile within a SHMS in order to detect structural changes within building materials

\section{The Design of the Weave:}

\section{Optimisation of choice of weave and yarns:}

We began by weaving a variety of sample textiles using a variety of weaves and yarns for testing by Nanoforce to analyse continuity and stability of the transmitted data from the incorporated stain sensitive yarn. This would allow for analysis of the weave types and yarns in order to make a choice of the optimal weave pattern and material choice for a SHMS. The sample designs were made holding in mind the premise that the structure of the weave would affect the way the polymer functioned within the textile.

Initial meetings at Nanoforce set the parameters for the first set of woven samples. Based on the data acquisition instruments that Nanoforce would provide for the testing, the samples were to be made as $10 \mathrm{~cm} \times 30 \mathrm{~cm}$ rectangular pieces. 28 samples were woven with different structures - plain weave, sateen, hopsack, twill and float, using varying combinations of two types of carbon nanotube polymer. One, thermoplastic polyurethane/carbon nanotube (TPU/CNT) with higher level of stretch and the other, Polybutylene Terepthalate (PBT) with a lower level of stretch, with a choice of two types of weft comaterial, nylon monofilament and elastic. The nylon was chosen for the fabric designs due to its strength, durability and compatibility with building composites. The stretch value of the elastic was identified as a characteristic that may work alongside the stretch value of the CNT polymer or produce interesting results with the lower stretch PBT. The structures were chosen as they embedded the yarns within the structure of cloth to varying degrees and tensions. The premise was that these would produce different readings and influence the performance of polymer.

Within the construction industry plain weave is used for lightweight, noncoated membranes. Hopsack weave is most commonly used for thicker, coated tensile membranes because the reduced waviness (undulation) of the threads results in a material with lower creep under high loads and because of the reduced disparity in the stiffness between the warp and weft directions. The fibre reinforced concrete industry are in particular, using non-crimp fabrics and 
leno weave as they offer a uniform load transfer and textile durability due to the lack of yarn slippage. As the fibres are not integrated into an undulating form, the mechanical strength is improved. The fibres can also can be woven at an angle to each other and so be placed in the load bearing directions, again increasing the strength of the cloth.

Plain weave was chosen as the most generic type of weave that tightly holds the weft yarn within the structure with equal warp/ weft value (Fig. 8). The 2/2 plain twill structure produces a stable but more malleable 'diagonal' cloth to that of plain weave (Fig. 9). The polymer is held less tightly within the structure, thus putting less pressure on it and giving it more space to move around. 4/4 and 8/8 versions were also created increasing the movement of the polymer within the structure. Hopsack was woven in two scales 4/4 (Fig. 10a, 10b) and 8/8 (Fig. 11). The hopsack is characterised by it being a scaled up version of plain weave - woven more loosely depending on the warp to weft values. The $8 / 8$ hopsack allowed the polymer to move around very freely within the cloth and the 4/4 with less ease. Sateen was chosen as this structure pins the polymer to the cloth with a ratio of one warp thread to seven, thus exposing a large surface area of the polymer on the fabric surface and holding it relatively loosely to the surface of the fabric (Fig. 12). A float structure was woven- this structure has areas of tightly woven plain weave and areas where the polymer would float over a collection of warp threads entirely giving two structural values within one cloth (Fig. 13).

\section{Testing data stability of textile samples in static state:}

NanoForce tested the textile samples as a static condition. The strain sensitivity of the specialized yarn is estimated by simultaneously measuring the conductivity change of the yarn when subjected to strain. The conductivity was measured by a two-point method which is a combination of a picoameter (Keithley 6485) and a DC voltage source (Agilent 6614C) (Fig. 14). The strain profile was set by a computer- controlled Instron tensile test machine. The monofilament sample was placed between pneumatic tensile grips, which are equipped with brass plates electrodes in order to guarantee good electrical contact (Fig. 15). The data was visualised as clearly readable graphs (Fig.16). The testing of the first experiments gave answers as to whether the strength of the warp relative to the weft distorts the reading and whether some of the woven samples hold the strain sensitive polymer in only one direction, so restricting the transmitted data.

Of the 28 initial sample, the five most stable weaves were chosen to further modify and test. They were:

- TPU/CNT Continuous Weft with nylon PLAIN WEAVE FLOAT structure (Fig. 17)

- TPU/CNT Continuous Weft with nylon with 16 SATEEN structure (Fig. 18)

- TPU/CNT Continuous Weft with elastic and nylon with 4X4 HOPSACK structure (Fig. 19)

- TPU/CNT Continuous Weft with elastic with 4X4 HOPSACK structure (Fig. 20)

- TPU/CNT Continuous Weft with nylon with 8x8 HOPSACK structure (Fig. 21) 
Hopsack is a loosely woven, open weave. Float structure is where a length of yarn is left to lie on the surface of a fabric over several consecutive threads. Sateen is a loose weave with no prominent weave structure and with less binding points and more float lengths. The most stable of these five was the sateen structure. As sateen is a weave with low yarn-to-yarn friction it allows the specialist yarn to be loosely woven onto the surface. It does not float separately but is less integrated than many of the other textile samples, allowing for slippage as the yarn is less constrained by the warp and weft and so there is a less complex pattern of stresses and strains applied to each yarn revealed by the data, thus showing more consistency. It is characterised by its excellent drapeability and in fibre reinforced polymers it is used for components with tight radii in order to achieve smooth surfaces. This would allow for ease of application to construction details (Knippers, Cremers and Gabler 2011).

Looking at the choice of yarns used, all five of the most stable samples had used the strain sensitive sensor fabricated as TPU/CNT and not as PBT so appearing to favour increased elasticity. It was posited that the ability to be more responsive to the strains applied to the yarn allowed for more stability in data transference. However, there is no consistency of the choice of co-material in the results, varying between elastic and nylon and so further analysis of the comaterial would be needed.

These five swatches were chosen to refine and replicate for further testing, to better understand the choice of co-material but also to investigate their histories - to analyze whether the data output not only depends on the current input but also on the history of the input. They were fabricated to a sample size for testing at Nanoforce, and at larger sample sizes for incorporation into a flexible, composite material to allow testing future application onto structural components of a building (Fig. 22).

\section{Testing data stability of yarn in dynamic state:}

Our tests to date have been with the textile under a static state. We needed to establish if this particular strain sensitive yarn could transmit data under a dynamic condition and whether this data could be gathered using remote radio Bluetooth technology. In a separate project, Structural Health Autonomic Kinetics for Earth Shifts (SHAKES), a computing platform was produced and tested to transmit data from the nano fibre via RFID technology, to a remote computer. The yarn was embroidered to the surface of a textile and placed on both a static and a vibrating surface. The findings showed that a computing platform could be produced to "transmit data from the nano fibre woven in a particular density in a particular structure, using RFID technology" (Farrer and Goulevand, 2014). This was successful both in a static and dynamic situation.

Following the analysis of the woven textiles, alongside the findings from SHAKES, an optimized textile will be produced for further testing to ascertain the accuracy with which complex structural movement can be read when the textile is integrated into a building structure, and to further understand the ways in which the polymer behaves and transmits data in a woven structure under a dynamic force. From these findings, the polymer itself can be modified by 
Nanoforce to suit precise structural situations and performance specifications. Other material considerations that require further exploration are how the comaterial, when within the woven cloth, will affect the performance of the cloth as a whole, in terms of (1.) stretch performance of co-material, (2.) degradability of material when in contact with other building materials and (3.) effect of moisture on polymer and co-material.

\section{Summary and Outlook}

The project has taken a conductive nanotube polymer composite that can sense strain and has placed it into a woven textile. Through the fabrication and testing of multiple types of weave and mix of yarns, the optimisation of the textile has developed for the weave to hold the strain sensitive thread whilst allowing constant transmission of data in a stable condition. Initial tests show that the yarn can continue to conduct data under a dynamic state. Early prototypes show that the textile can be bedded into a protective silicone coating. The research team, throughout the fabrication process, took the aesthetic of the textile into consideration, both in the choice of yarns and in any suggested placement of the composite within a building system. The future visual impact of the application of the textile within a building system was considered alongside technical functionality, to enhance usability through visual clarity. The next stage is to test the fabric as a resin based composite, laminated to a section of a building element in both a static and dynamic state. During future testing the mechanical properties of the textile will be customised through the choice of weave and yarn, to suit the local performance specification required of specific building elements. The project has developed, from yarn to textile to composite and is underpinned with technical data for conductive textile construction. This research shows the potential to continue to develop a SHMS as a woven textile for use in the construction industry.

\section{References}

Adanur, S., Tewari. A., (1997) An Overview of Military Textiles. Indian Journal of Fibre and Textile Research Vol 22, December 1997, pp. 348-352

Ahlquist, S., Menges A. (2013). “Frameworks for Computational Design of Textile Micro-Architectures and Material Behaviour in Forming Complex ForceActive Structures". ACADIA, 281-292.

Ahlquist, S., Lienhard, J., F., Knippers, J., Menges, A. 2013. “Exploring Materials Reciprocities for Textile-Hybrid Systems as Spatial Structures", in Stacey, M. (Ed.), Prototyping Architecture: The Conference Papers, Building Centre Trust, London. 187-210. (ISBN 978-0-901919-17-5).

Bartels. V.T. (Ed). 2011. Handbook of Medical Textiles. The Textile Institute.

Woodhead Publishing. 
Braddock, S., O’Mahoney, M. 1999. Techno Textiles: Revolutionary Fabric and Fashion. Thames \& Hudson.

Braddock, S. 2007. Techno Textiles 2: Revolutionary Fabric and Fashion. Thames \& Hudson.

Clemens, F., Mattman, C., Troster, G. 2008. “Sensor for Measuring Strain in Textile." Sensors, 8: 3719-3732

Chawda, B., Craft, B., Cairns, P. 2005. "Do "Attractive Things Work Better"? An Exploration of Search Tool Visualisations". Proceedings of the 19th British HCI Group Annual Conference on The Bigger Picture. Edinburgh, UK, 4651.

Cheyne, K., (1996) Self-Monitoring and Self-Healing Structures: Intelligent Webs and Nano-Sand.

Dai, H., Schumacher, T., Thostenson, E. T. 2014. “Carbon Nanotube-Based Sensing Composites for Structural Health Monitoring of Civil Infrastructure Using Non-Woven Fabrics. Safety, Reliability, Risk and Life-Cycle Performance of Structures and Infrastructures". Proceedings of the 11th International Conference on Structural Safety \& Reliability (ICOSSAR 2013). New York, NY, 2013. CRC Press

Garcia, M., (Ed.). 2007. Architextiles AD, Academy Press; 1edition

Farrer,J., Goulev. P.,Parr ,H. 2014. “Intelligent Textiles; Structural Health Autonomic Kinetics for Earth Shifts (SHAKES)", Presented at 43 ${ }^{\text {rd }}$ Textile Research Symposium, Christchurch, New Zealand

Hehr, A., Schulz, M., Shanov. V., Song, Y. 2014. “Micro-crack detection and assessment with embedded carbon nanotube thread in composite materials". Structural Heath Monitoring. Vol. 13(5): 512-524

Hertleer, C., Schwar, A., Van Langenhove, L. 2012. "Smart Textiles: An Overview”. NATO Science for Peace and Security Series B: Physics and Biophysics, 119136

Knippers, J., Cremers, J., Gabler, M., Lienhard, J. 2011. Plastics + Membranes Construction Manual. Birkhauser

Leng, J., Asundi, A. 2002. "Structural Health Monitoring of Smart Composites Materials by using EFPI and FBG Sensors". Sensors and Actuators A, 103: $330-340$ 
McDougall, K. 2011. "A case study in innovation in contemporary tweed".

Norman. D. 2002. Emotional Design: Attractive things work better. Interactions Magazine, ix(4): 36-42

Norman. D. 2007. Emotional Design: Why we love (or hate) everyday things. Basic Books

Norman. D., Verganti. R. 2014. "Incremental and Radical Innovation: Design Research versus Technology and Meaning Change". Design Issues, 30(1)

Otto, F. 1974. Tensile Structures: v.1 \& 2, MIT Press

Pailes-Friedman, R. 2016. Smart Textiles for Designers: Inventing the Future of Fabrics, Lawrence King

Ramsgaard Thomsen, M., Tamke, M., Holden Deleuran, A., Schmeck, M., Quinn, G., Gengnagel, C., Tamke, M., Ramsgaard Thomsen, M. 2015. “The Tower: Modelling, Analysis and Construction of Bending Active Tensile Membrane Hybrid Structures". In Proceedings of the International Association for Shell and Spatial Structures (IASS) Symposium 2015, Amsterdam - Future Visions, 17 - 20 August 2015, Amsterdam, The Netherlands

Sawhany, Condon, Singh, Pang, Li and Hui. 2008. "Modern applications of Nanotechnology in Textiles"

Trindade, I., Spranger, P., Martins, F., Miguel, R., Santos Silva, M. 2014. "Fully Integrated Embroidery Process for Smart Textiles". Nanotech, Vol 3:65-68

West, M. 2016. The Fabric Formwork Book: Methods for Building New Architectural and Structural Forms in Concrete. Taylor \& Francis Ltd Zhang, R., Bilotti, E., Deng, H., Baxendale, M., Peijs, T. 2009. "Fabrication and Property Prediction of Conductive and Strain Sensing TPU/CNT Nanocomposite Fibres". Journal of Materials Chemistry, 20: 9449-9455

Websites

https://www.vam.ac.uk/articles/about-the-elytra-filament-pavilion

http://www.treehugger.com/sustainable-fashion/10-awesome-innovationschanging-future-fashion.html

http://www.scoop.it/t/art-installations?page=2\&tag=textile 
http://journal.fashionspyder.com/the-3d-print-boom-in-fashion-design/ http://www.detail-online.com/article/london-2012-olympic-shooting-venues$\underline{16398 /}$

http://www.scientificamerican.com/article/americas-cup-fixed-wing-sail/ http://www.mclaren.com/group/case-studies/case-study-carbon-fibre/ http://www.reillycycleworks.com/pages/carbon-frame-production http://www.stressuk.co/carbon/brighton-royal-pavillion/ http://www.omega.co.uk/prodinfo/strain-gauges.html 


\section{Appendix}

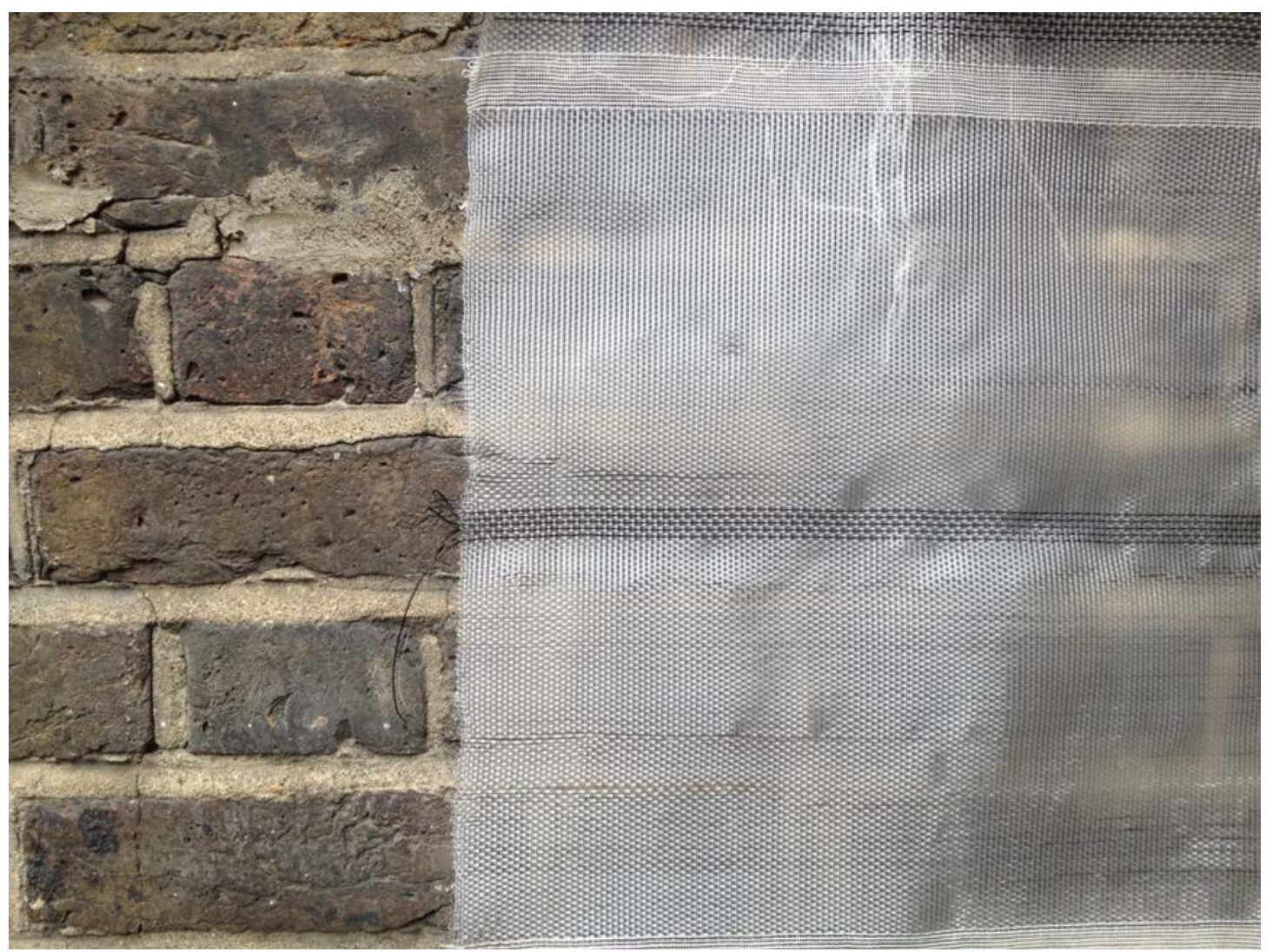

Figure 1: Textile Membrane 


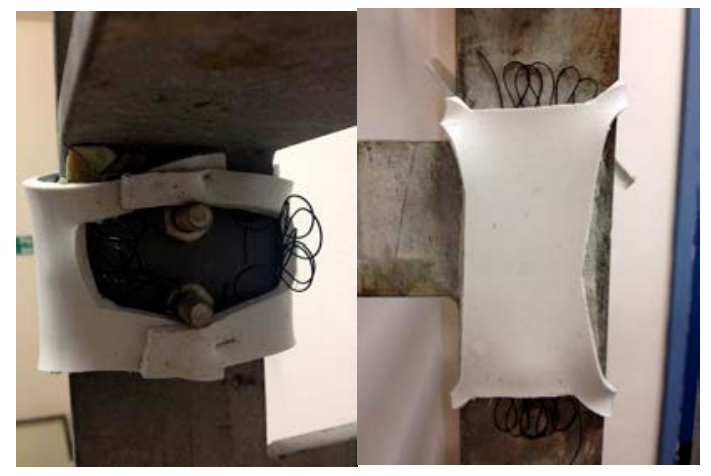

Figure 2a, 2b Localised Textile Bandage 


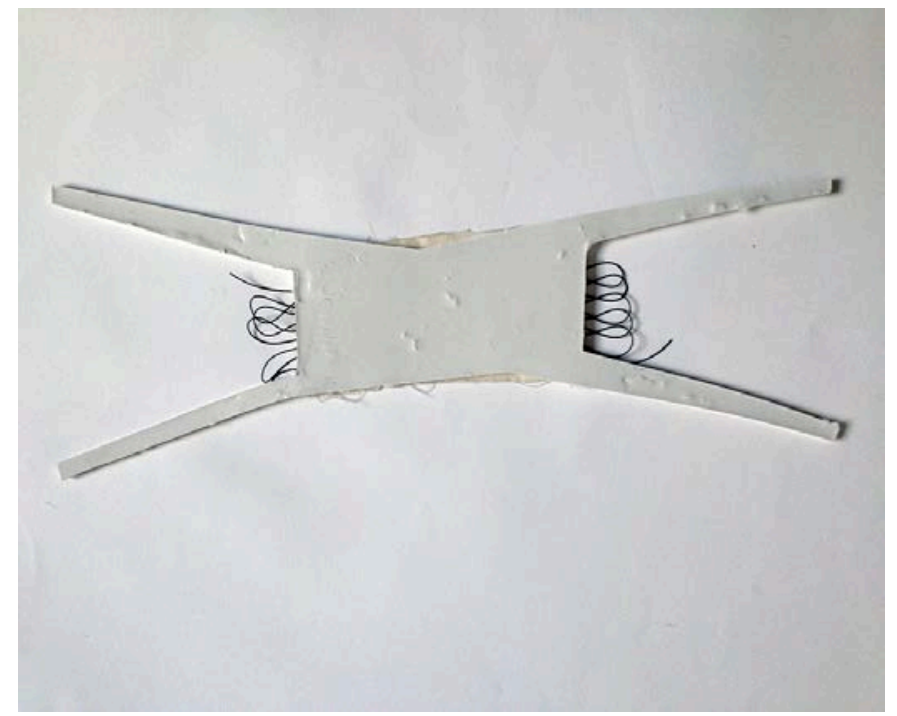

Figure 3: Protective Coating 


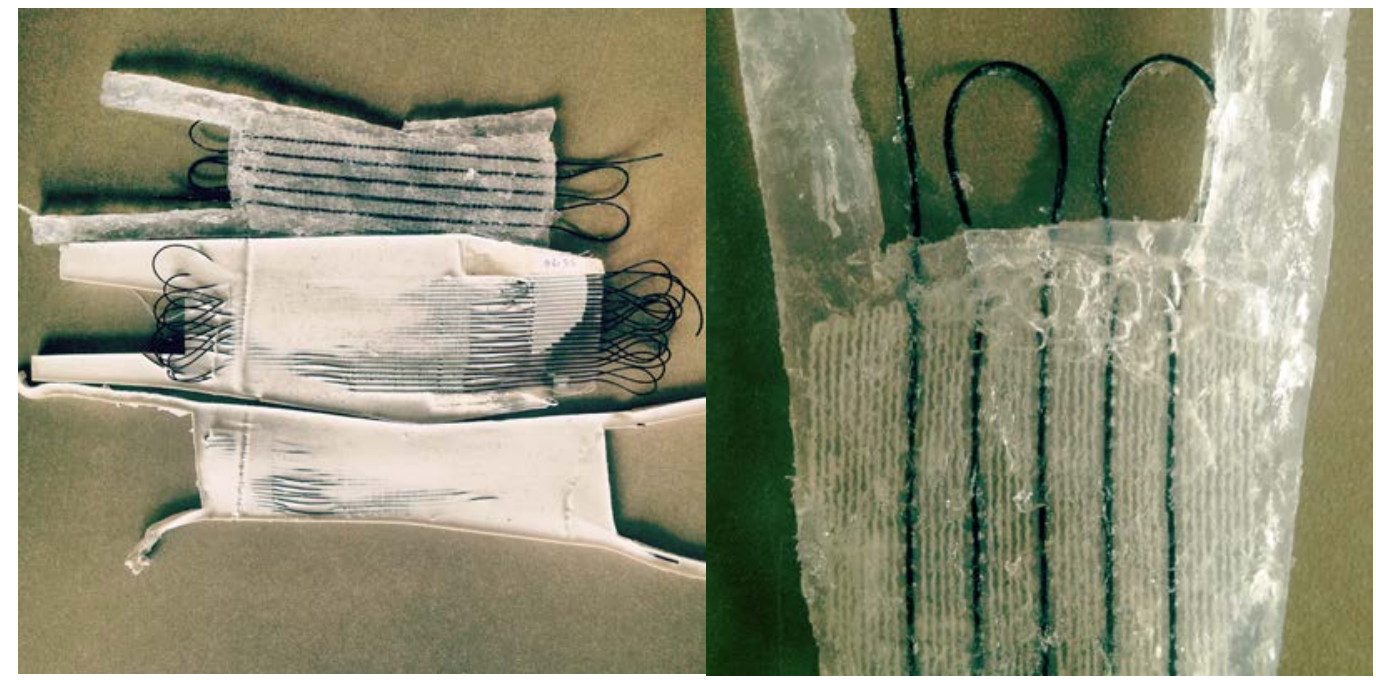

FIGURE 4a, 4b: Example of Early Composite Textile 


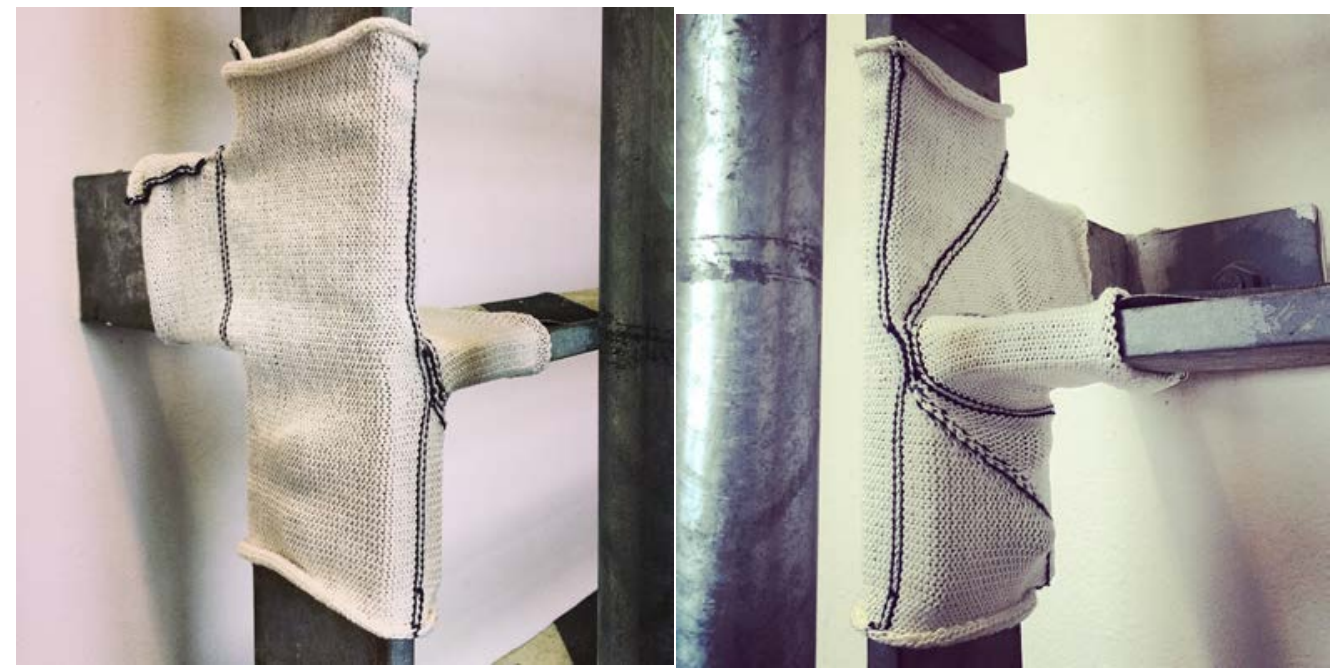

FIGURE 5a, 5b: Example of Early 'Textile Gloved Joint' 


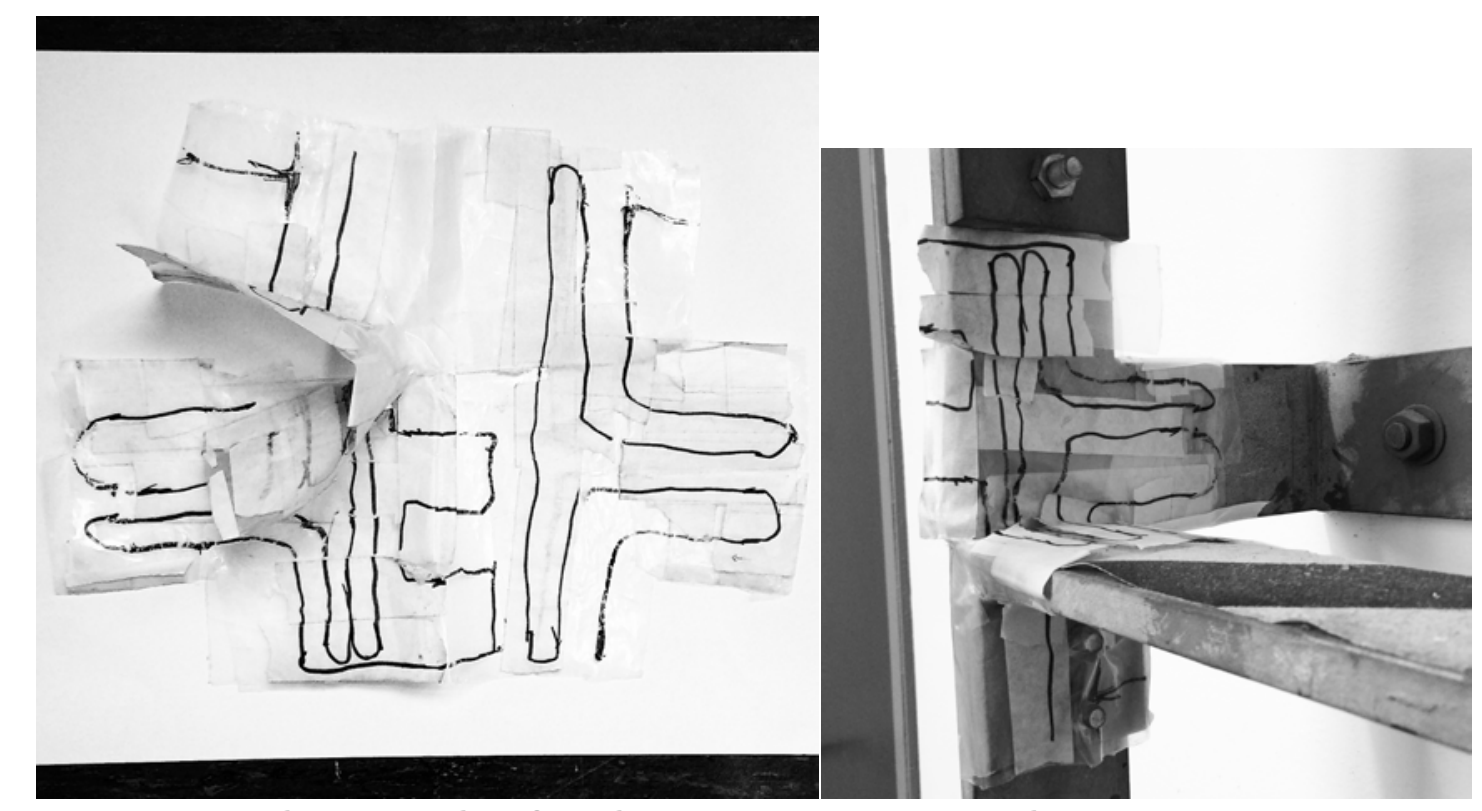

FIGURE 6a, 6b: Example of Early Pattern Cutting Technique 


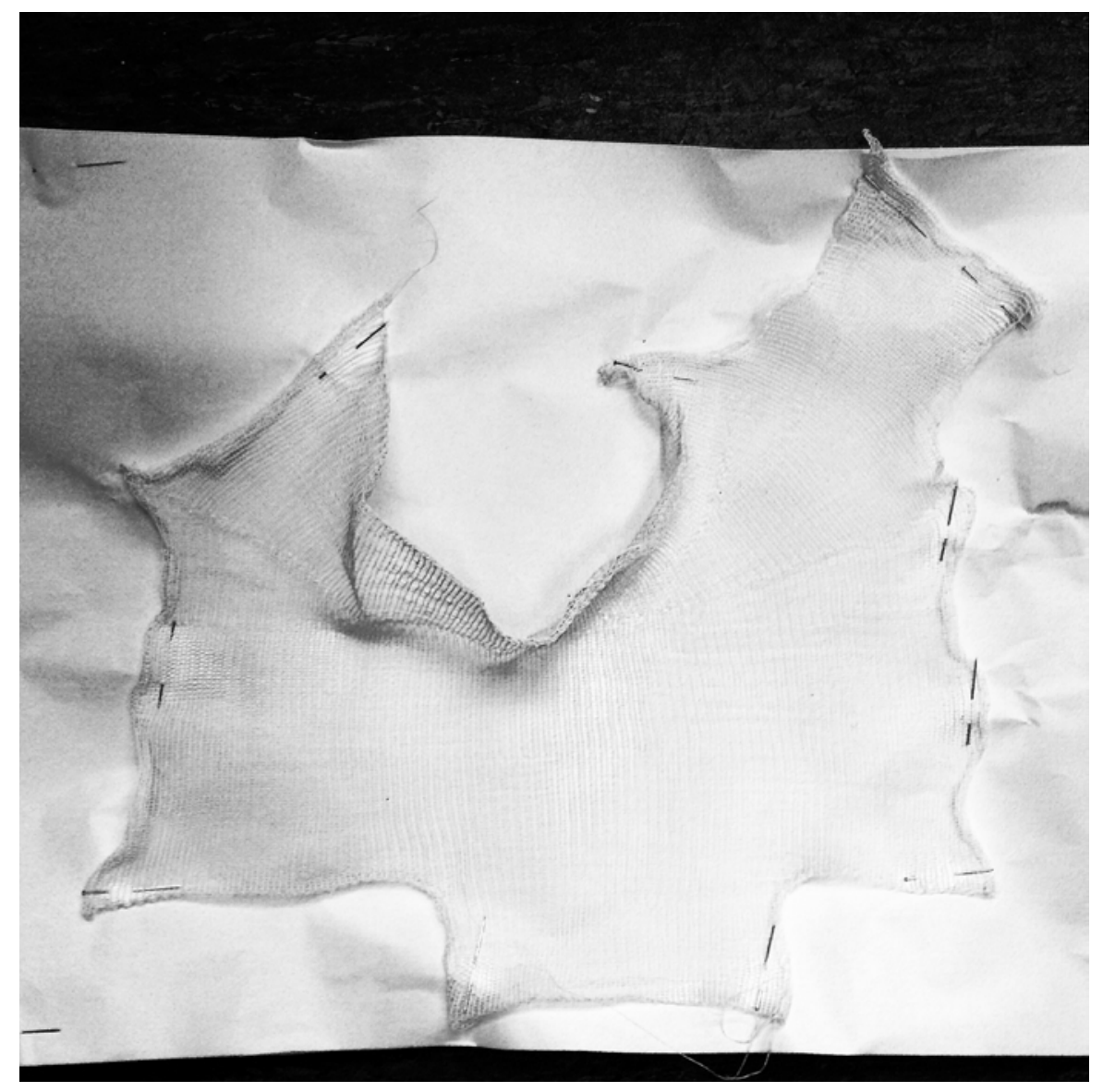

FIGURE 7: Example of Early 3D 'Glove Joint’ 


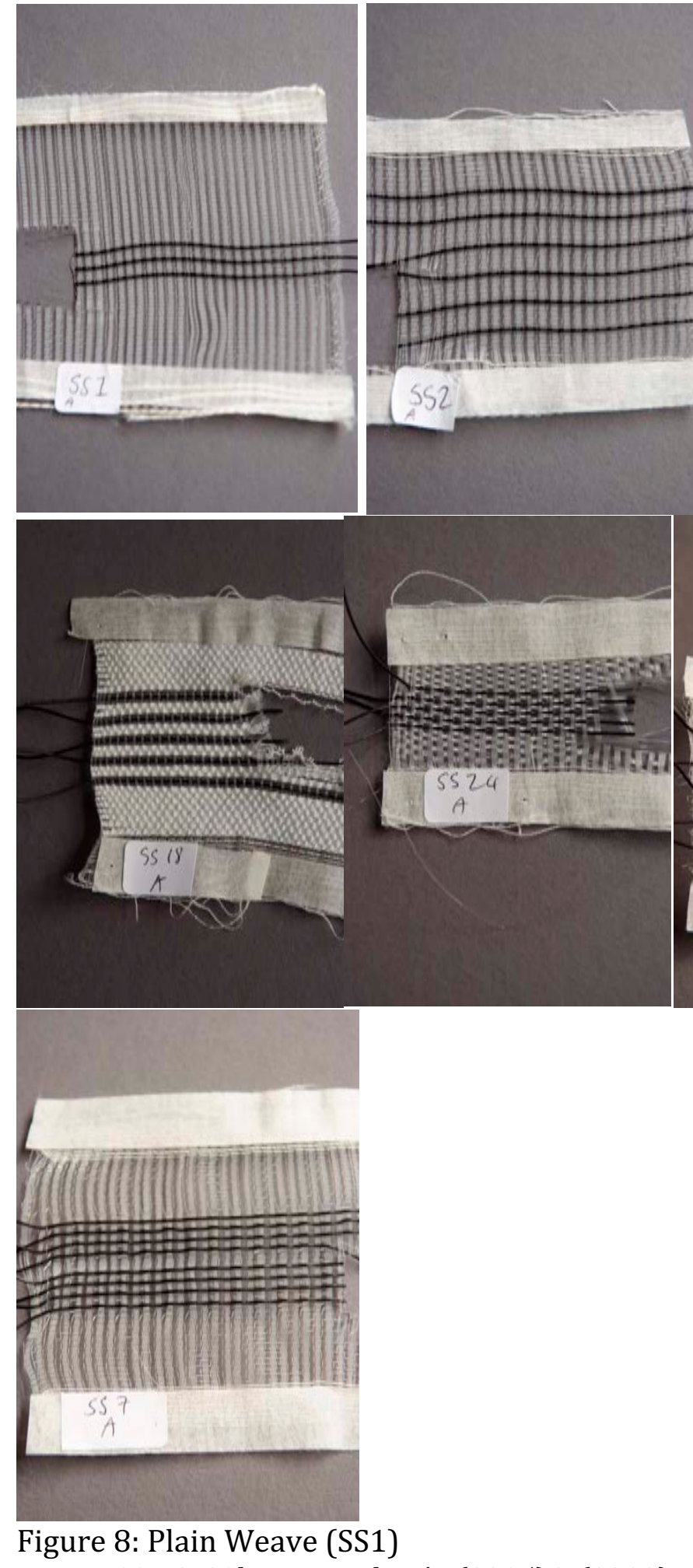

Figure 10a \& 10b: Hopsack 4/4 (SS15)\& (SS18) Figure 12: Sateen (SS13)
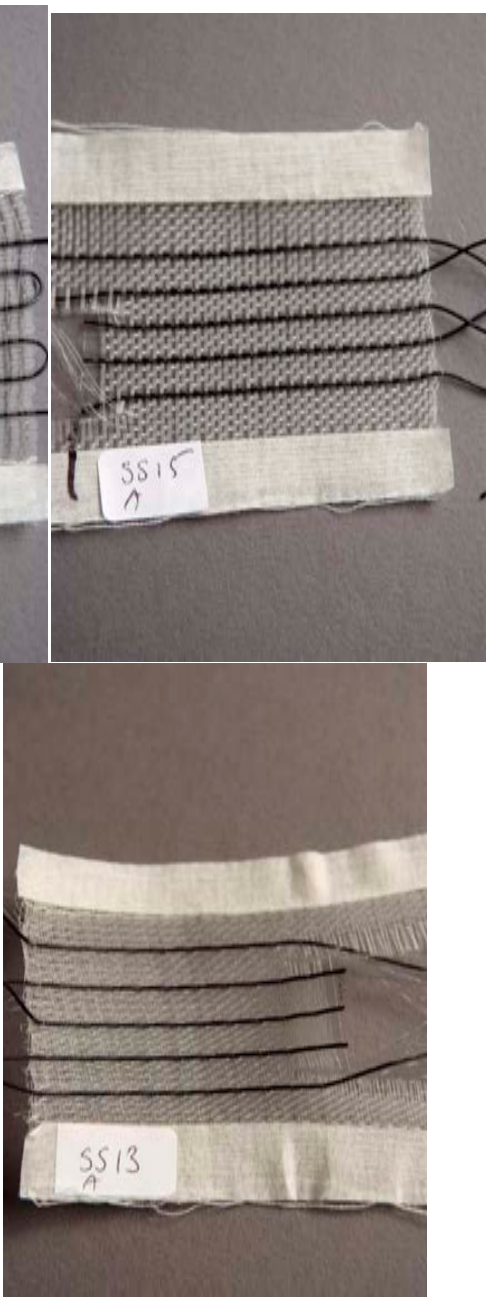

Figure 9: Plain Twill 2/2 (SS2)

Figure 11 Hopsack 8/8 (SS24)

Figure 13: Float (SS7) 


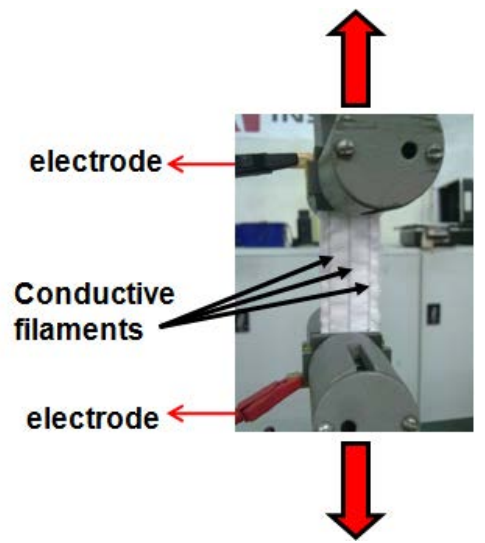

Figure 14: Schematic of strain-sensing set-up 


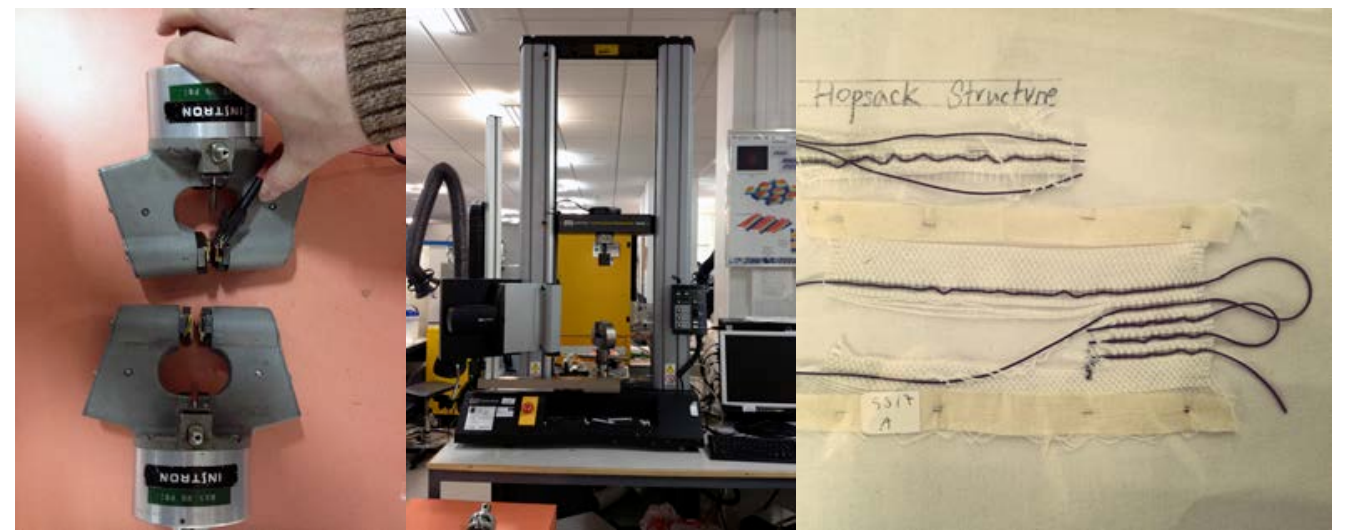

Figure 15: Example of initial sample for testing and Nanoforce laboratory 
Figure 16: Graphs

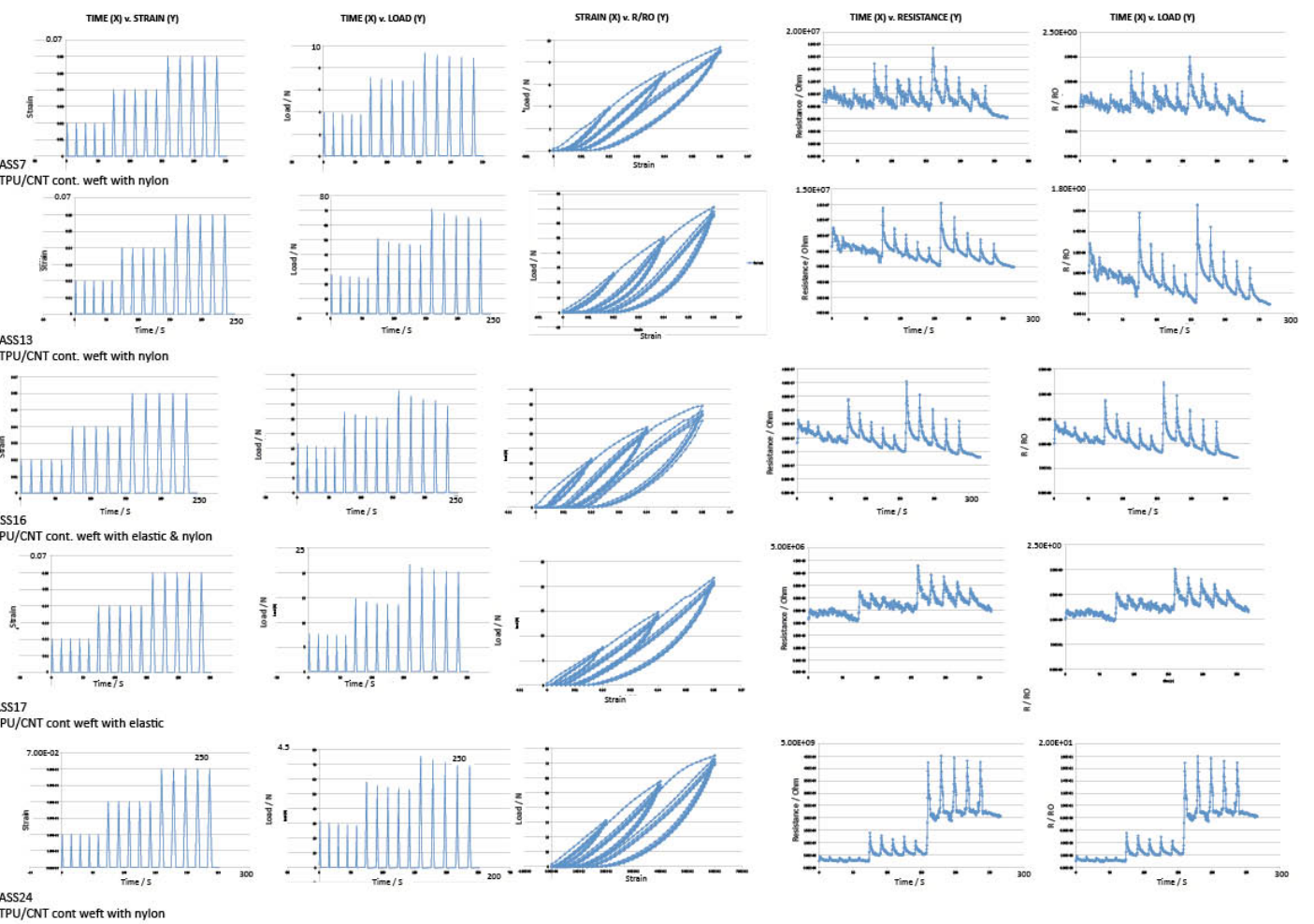




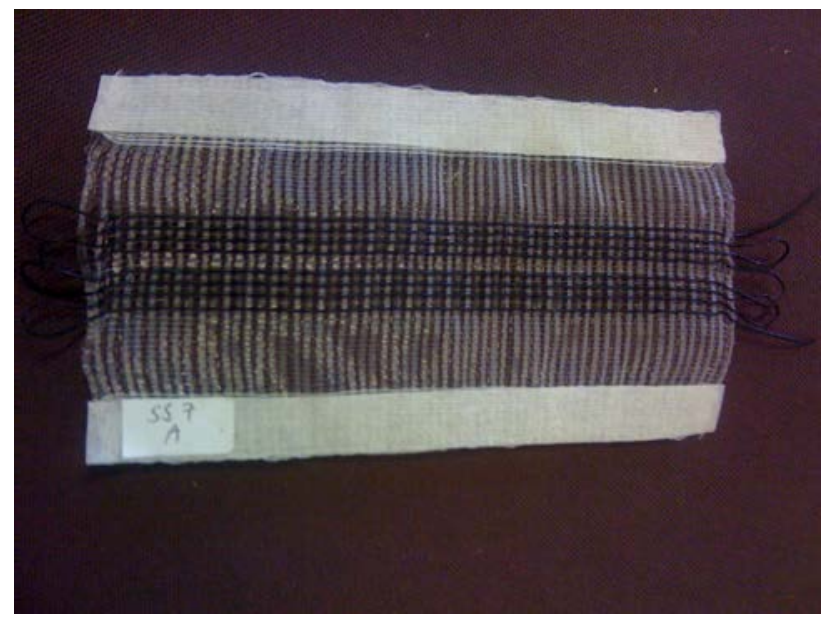

Figure 17: Float Structure: TPU/CNT Continuous Weft with nylon

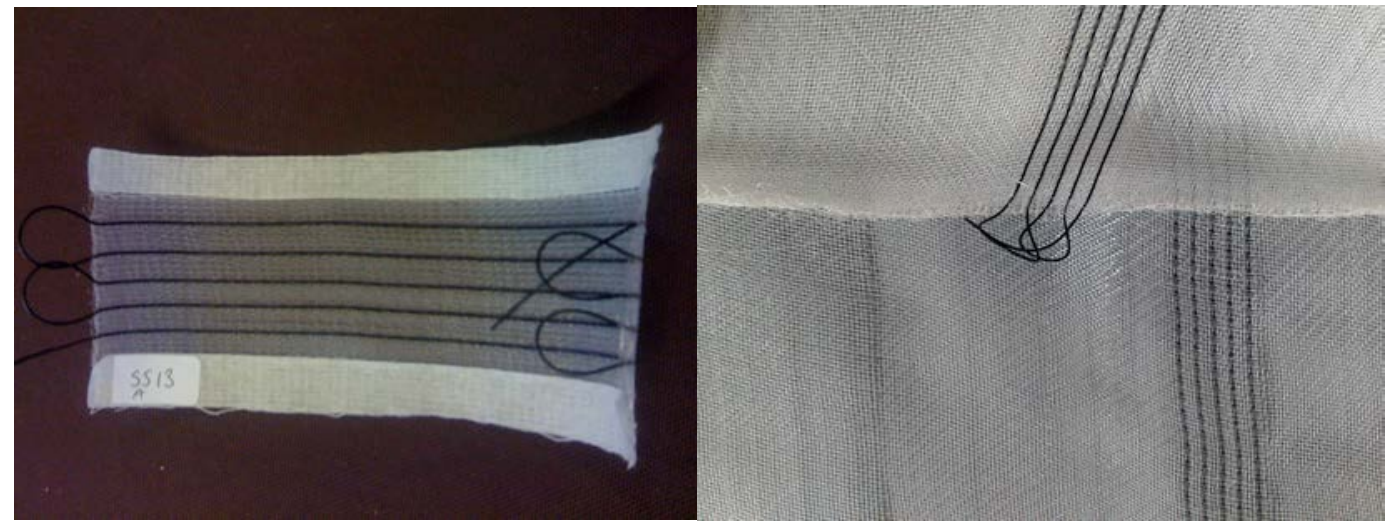

Figure 18: Sateen Structure TPU/CNT Continuous Weft with nylon 


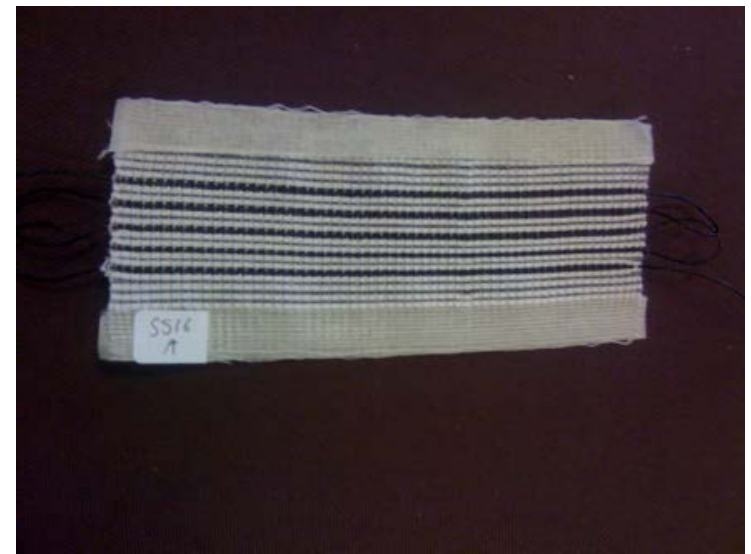

Figure 19: 4/4 Hopsack Structure: TPU/CNT Continuous Weft with elastic and nylon 


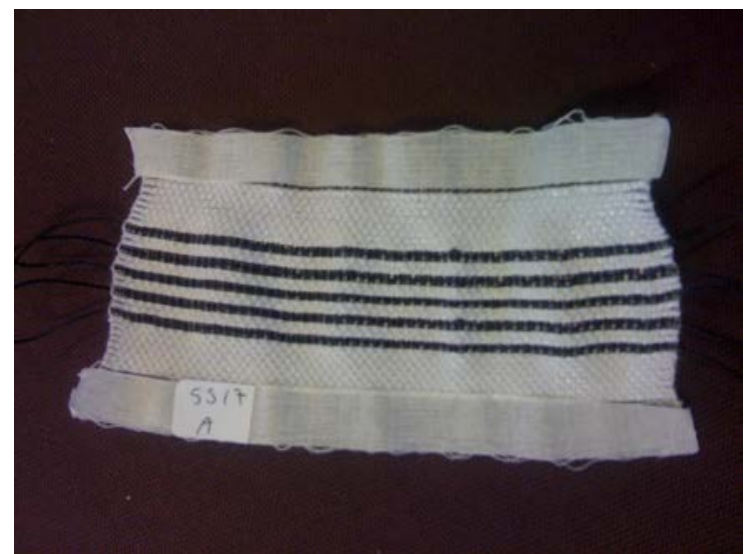

Figure 20: 4/4 Hopsack Structure: TPU/CNT Continuous Weft with elastic 


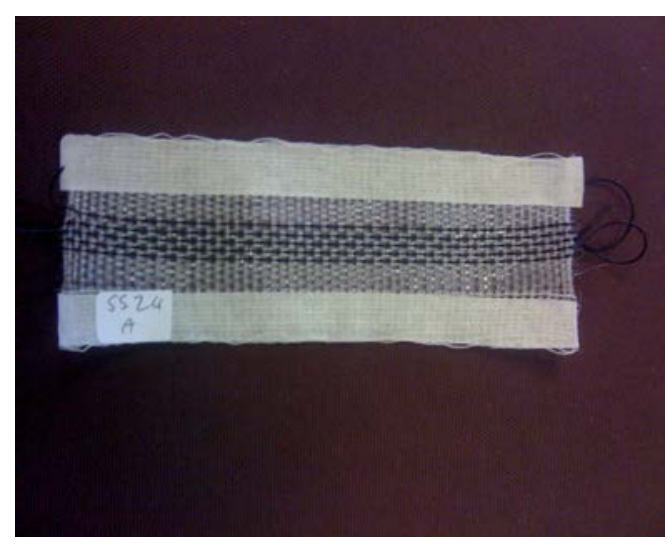

Figure 21: 8/8 Hopsack Structure: TPU/CNT Continuous Weft with nylon 


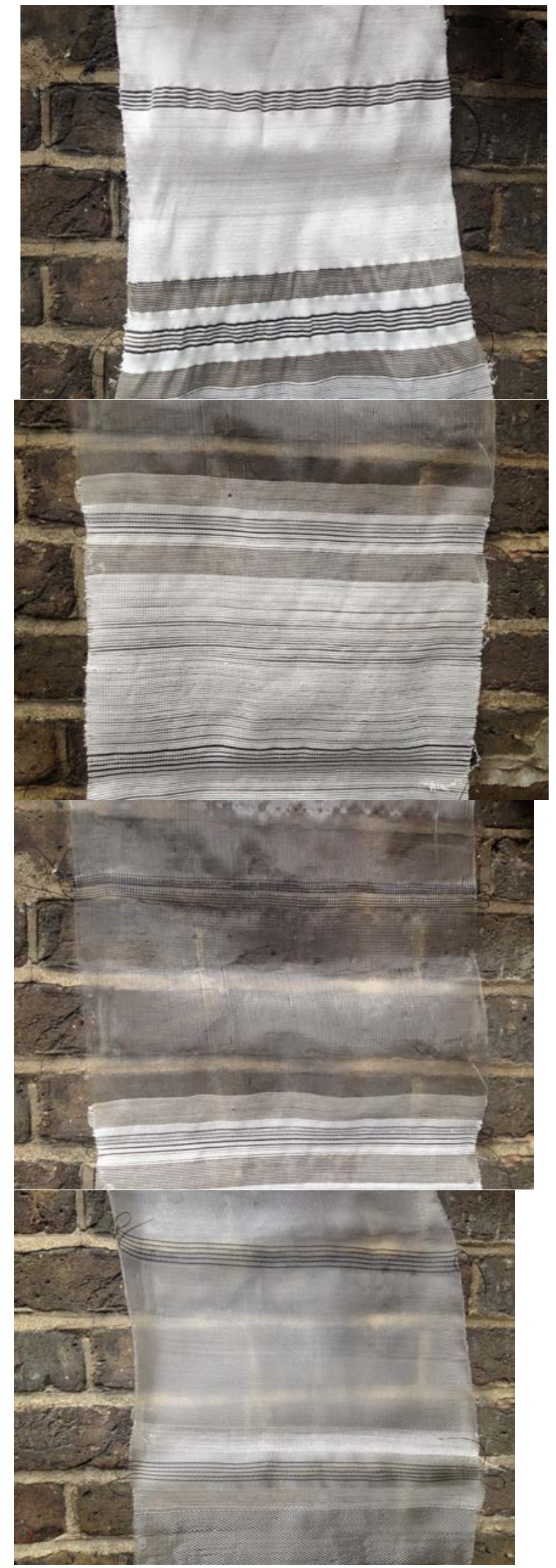

FIGURE 22: Example of Larger Samples for Composite Integration 
Thanks:

This paper was developed from a presentation given at the Transition:

Rethinking Textiles and Surfaces Conference at the University of Huddersfield. We would like to thank the University of Brighton for the initial funding through the Research Challenges Scheme and Dr Joan Farrer and Professor Susannah Hagan for mentoring us through the project. In particular we thank Nanoforce for providing the nano tech. strain-sensitive thread and testing the samples. Thanks also go to Pierfrancesco Cacciola from the University of Brighton School of Environment \& Technology for engineering consultancy and Dr Ben Sweeting for his editorial support with the paper. A final thanks to Faith Kane for her patience in waiting for this paper and with its final edit and Marina Debattista for the production edit. 